\title{
\& Research Square \\ Three-Body Photodissociation of Water Molecule: An Important Prebiotic Oxygen Source
}

\section{Yao Chang}

Dalian Institute of the Chemical Physics https://orcid.org/0000-0002-2747-8499

\section{Yong Yu}

Dalian Institute of Chemical Physics

\section{Feng An}

Nanjing University

\section{Zijie Luo}

Dalian Institute of the Chemical Physics

\section{Donghui Quan}

Eastern Kentucky University

\section{Xia Zhang}

Xinjiang Astronomical observatory

\section{Xixi Hu}

Nanjing University https://orcid.org/0000-0003-1530-3015

\section{Qinming Li}

Dalian Institute of Chemical Physics

\section{Jiayue Yang}

Dalian Institute of Chemical Physics, Chinese Academy of Sciences

\section{Zhichao Chen}

Dalian Institute of the Chemical Physics

\section{Li Che}

Dalian Maritime University

\section{Weiqing Zhang}

Dalian Institute of Chemical Physics

\section{Guorong Wu}

Dalian Institute of Chemical Physics, Chinese Academy of Sciences. https://orcid.org/0000-0002-

0212-183X

\section{Daiqian Xie}

Nanjing University https://orcid.org/0000-0001-7185-7085

\section{Michael Ashfold}

University of Bristol https://orcid.org/0000-0001-5762-7048

\section{Kaijun Yuan ( $\nabla$ kjyuan@dicp.ac.cn )}

Dalian Institute of the Chemical Physics https://orcid.org/0000-0002-5108-8984 


\section{Xueming Yang}

Dalian Institute of Chemical Physics https://orcid.org/0000-0001-6684-9187

\section{Article}

Keywords: Photochemistry, Vacuum Ultraviolet Photodissociation, Three-body Dissociation, Free Electron Laser, Interstellar Photochemical Models

Posted Date: January 4th, 2021

DOl: https://doi.org/10.21203/rs.3.rs-124069/v1

License: (c) (1) This work is licensed under a Creative Commons Attribution 4.0 International License. Read Full License

Version of Record: A version of this preprint was published at Nature Communications on April 30th, 2021. See the published version at https://doi.org/10.1038/s41467-021-22824-7. 


\section{Abstract}

The provenance of oxygen on the Earth and other Solar planetary bodies is a fundamental issue. It has been widely accepted that the only prebiotic pathway to produce oxygen in the Earth's primitive atmosphere was via vacuum ultraviolet (VUV) photodissociation of $\mathrm{CO}_{2}$ and subsequent two $\mathrm{O}$ atom recombination. Here, we provide experimental evidence of three-body dissociation (TBD) of $\mathrm{H}_{2} \mathrm{O}$ to produce $\mathrm{O}$ atoms in both ${ }^{1} \mathrm{D}$ and ${ }^{3} \mathrm{P}$ states upon vacuum ultraviolet (VUV) excitation using the newly developed tunable VUV free electron laser. Experimental results show that the TBD is the dominant pathway in the VUV $\mathrm{H}_{2} \mathrm{O}$ photochemistry at wavelengths between 90 and $107.4 \mathrm{~nm}$. The relative abundance of water in the interstellar space with its exposure to intense VUV radiation suggests that the TBD of $\mathrm{H}_{2} \mathrm{O}$ and subsequent $\mathrm{O}$ atoms recombination should be an important prebiotic $\mathrm{O}_{2}$-production, which may need to be incorporated into interstellar photochemical models.

\section{Introduction}

Oxygen is the third most abundant element in the Universe, but its molecular form $\left(\mathrm{O}_{2}\right)$ is very rare. Besides on the Earth, molecular oxygen has only been detected in two interstellar clouds[1] ${ }^{[2]}$, in the moons of Jupiter[3] and Saturn[4], and on Mars[5]. Geologically based arguments suggested that Earth's original atmosphere had no oxygen and was composed mostly of $\mathrm{H}_{2} \mathrm{O}, \mathrm{CO}_{2}$, and $\mathrm{N}_{2}$, with only small amounts of $\mathrm{CO}$ and $\mathrm{H}_{2}[6]$. Therefore, how oxygen is produced in the primitive atmosphere is a fundamentally important issue in the evolution of the early primitive atmosphere. Before the emergence of the oxygen-rich atmosphere due to the "great oxidation event" (GOE) [7] ${ }^{[8]}$, about 2.33 billion years ago, which allowed the Earth to evolve into a living planet, a small amount of oxygen was already present, and this was previously attributed to an abiotic formation mechanism involving photodissociation of $\mathrm{CO}_{2}$ by vacuum ultraviolet (VUV) light, followed by three-body recombination processes[9],

$\mathrm{CO}_{2}+h v \rightarrow \mathrm{CO}+\mathrm{O}$

$\mathrm{O}+\mathrm{O}+\mathrm{M} \rightarrow \mathrm{O}_{2}+\mathrm{M}$

where $\mathrm{M}$ is a third body to carry off the excess energy in the reaction process. Direct $\mathrm{O}_{2}$ production pathways via VUV photodissociation of $\mathrm{CO}_{2}[10]$ and dissociative electron attachment to $\mathrm{CO}_{2}[11]$ have recently been identified. These findings provide new insights into the sources of $\mathrm{O}_{2}$ in Earth's early atmosphere.

In contrast, photodissociation of $\mathrm{H}_{2} \mathrm{O}$, one of the dominant oxygen carriers[12], has long been assumed to proceed mainly to produce hydroxyl $(\mathrm{OH})$ and hydrogen $(\mathrm{H})$ atom primary products, and contribute limited to the $\mathrm{O}_{2}$ production ${ }^{9}$. Recently, abundant molecular $\mathrm{O}_{2}$ in the coma of comet $67 \mathrm{P} /$ ChuryumovGerasimenko (one of typical solar planetary bodies), which is dominated by $\mathrm{H}_{2} \mathrm{O}, \mathrm{CO}$ and $\mathrm{CO}_{2}$, has been detected[13]. Interestingly, a strong correlation between $\mathrm{O}_{2}$ and $\mathrm{H}_{2} \mathrm{O}$ has been identified, indicating the $\mathrm{O}_{2}$ 
formation is linked to $\mathrm{H}_{2} \mathrm{O}$ in the comet. One plausible explanation for the strong $\mathrm{O}_{2}-\mathrm{H}_{2} \mathrm{O}$ correlation would be that the $\mathrm{O}_{2}$ is produced by radiolysis or photolysis of water, or single collisions of energetic $\mathrm{H}_{2} \mathrm{O}^{+}$with surfaces[14]. However, the existing photochemical reaction mechanisms seem hard to predict the measured $\mathrm{O}_{2}$ abundance ${ }^{13}$. Thus, the detailed $\mathrm{O}_{2}$ production mechanism in the coma of comets is still unclear.

The photodissociation of water has been the subject of many experimental studies, which have revealed fascinating dynamics arising from strongly coupled electronic states with strikingly different potential energy surfaces (PESs)[15] ${ }^{[16]}$. Excitation to the first excited singlet $\left({ }^{1} \mathrm{~B}_{1}\right)$ state of $\mathrm{H}_{2} \mathrm{O}$ at wavelengths I $\sim 160 \mathrm{~nm}$ results in direct $\mathrm{O}-\mathrm{H}$ bond fission yielding an $\mathrm{H}$ atom plus a ground state hydroxyl radical, $\mathrm{OH}$ $\left(X^{2} \Pi\right)$, with little internal excitation[17];[18],[19]. The absorption cross-section to the second excited singlet ( ${ }^{1} \mathrm{~A}_{1}$ ) state is maximal at $\mathrm{I} \sim 128 \mathrm{~nm}$. Excitation at these wavelengths results in a (minor) direct dissociation channel to electronically excited $\mathrm{OH}\left(\mathrm{A}^{2} \Sigma^{+}\right)+\mathrm{H}$ products. The major dissociation process yields ground state $\mathrm{OH}(\mathrm{X})+\mathrm{H}$ products following non-adiabatic transitions at conical intersections (Cls) between the and state PESs at linear $\mathrm{H}-\mathrm{O}-\mathrm{H}$ and $\mathrm{H}-\mathrm{H}-\mathrm{O}$ geometries[20]-[21],[22],[23].

Additional fragmentation pathways, named three-body dissociation (TBD), become accessible energetically at shorter photolysis wavelengths, e.g.

$\mathrm{H}_{2} \mathrm{O}+h v \rightarrow \mathrm{O}\left({ }^{3} \mathrm{P}\right)+\mathrm{H}+\mathrm{H} \quad(9.513 \mathrm{eV}) \quad \varangle 3 \rrbracket$

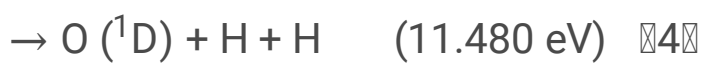

where the threshold energies $\left(E_{\mathrm{th}}\right)$ for these fragmentation channels are given in parentheses[24]. Fragmentation channel (3) has been previously detected with small quantum yields[25] [26] following photoexcitation of $\mathrm{H}_{2} \mathrm{O}$ at the Lyman-a wavelength $(I=121.57 \mathrm{~nm})$. Because of the lack of intense tunable VUV laser sources, quantitative assessment of the importance of the $\mathrm{H}_{2} \mathrm{O}$ TBD processes in the VUV region and its role in the $\mathrm{O}_{2}$ formation in the interstellar space has not been possible. Recent development of the new intense VUV free electron laser (FEL), at the Dalian Coherent Light Source (DCLS), has provided an exciting tool for experimental studies of molecular photochemistry throughout the entire VUV region[27]. Here we report novel studies of $\mathrm{H}_{2} \mathrm{O}$ photochemistry in the VUV region using the DCLS and the H-atom Rydberg tagging time-of-flight (HRTOF) technique. These experiments allow quantitative determination of the relative importance of the binary dissociation and the TBD processes following photoexcitation of $\mathrm{H}_{2} \mathrm{O}$ in the $90-110 \mathrm{~nm}$ region. The present results show conclusively that the $\mathrm{H}_{2} \mathrm{O}$ TBD process is an important pathway to form oxygen in the interstellar space.

\section{Results And Discussion}

The $\mathrm{H}_{2} \mathrm{O}$ sample is generated in a supersonic beam, with a rotational temperature estimated to be about $10 \mathrm{~K}$. The $\mathrm{H}_{2} \mathrm{O}$ molecules were photoexcited to different Rydberg states[28] (see Fig. S1 and S2 in the 
Supplementary Materials (SM))). The dissociated $\mathrm{H}$-atom fragments were then detected using the HRTOF technique (see Methods Section). TOF spectra of the $\mathrm{H}$ atoms resulting from $\mathrm{H}_{2} \mathrm{O}$ photodissociation at $\mathrm{I}=$ $107.4 \mathrm{~nm}$ have been recorded, with the detection axis aligned parallel and perpendicular to the polarization vector of the VUV FEL radiation. Knowing both the distance travelled by the $\mathrm{H}$ atom from the photodissociation area to the detector and its mass, the TOF spectra can be converted into the distributions of total kinetic energy release (TKER)[29]. Using the TKER distributions obtained in the parallel and perpendicular directions, we can construct a 3-dimensional (3D) flux diagram of the $\mathrm{H}$-atom fragments. Fig. 1 shows the 3D product flux diagrams in two regions of the kinetic energy with rich structures. The tall feature at low kinetic energy (Fig. 1A) shows a large product angular anisotropy, whereas the product anisotropy in the higher kinetic energy region (Fig. 1B), is rather small.

For detailed analysis and feature assignment, the TKER distributions in parallel and perpendicular directions at $\mathrm{I}=107.4 \mathrm{~nm}$ are plotted in Fig. $1 \mathrm{C}$, while the product TKER distribution from photodissociation of $\mathrm{H}_{2} \mathrm{O}$ at the magic angle (with detection angle of $54.7^{\circ}$ relative to the polarization direction) is shown in Fig. 1D. These distributions show both sharp and broad features. Using the energy conservation relationship appropriate for a binary photodissociation process,

$E_{h v}+E_{\text {int }}\left(\mathrm{H}_{2} \mathrm{O}\right)=D_{0}(\mathrm{H}-\mathrm{OH})+E_{\mathrm{KE}}(\mathrm{H}+\mathrm{OH})+E_{\mathrm{int}}(\mathrm{OH})$

where, $E_{\text {int }}\left(\mathrm{H}_{2} \mathrm{O}\right)$ and $E_{\text {int }}(\mathrm{OH})$ are the internal energies of $\mathrm{H}_{2} \mathrm{O}$ and $\mathrm{OH}$, respectively, $E_{\mathrm{KE}}$ is the product total kinetic energy and $D_{0}(\mathrm{H}-\mathrm{OH})$ is the dissociation energy of $\mathrm{H}_{2} \mathrm{O}[30]$. We can assign all of the sharp structures to specific ro-vibrational levels of the $\mathrm{OH}$ product in the $\mathrm{X}$ and $\mathrm{A}$ states formed via the binary dissociation channel, $\mathrm{H}+\mathrm{OH}(\mathrm{X}$ or $\mathrm{A}, \mathrm{v}, \mathrm{M})$. In addition to these sharp structures, the TKER spectra show two broad features: one with $E_{\mathrm{KE}} £ 600 \mathrm{~cm}^{-1}$ that has a large angular anisotropy, and an underlying feature that spans the range of $600 £ E_{\mathrm{KE}} £ 16000 \mathrm{~cm}^{-1}$ which displays a much smaller angular anisotropy. These broad features are obviously not from the binary dissociation channel, $\mathrm{H}+\mathrm{OH}$. Based on energy conservation, the maximum kinetic energy for the $\mathrm{H}$-atom product from the TBD channels (3) and (4) at $107.4 \mathrm{~nm}$ are $16448 \mathrm{~cm}^{-1}$ and $580 \mathrm{~cm}^{-1}$, respectively. These limits of the two TBD channels match well with the upper limits of the two broad features in the distributions (Fig. 1). Thus, the intense broad feature at $E_{\mathrm{KE}}<600 \mathrm{~cm}^{-1}$ is assigned to the $\mathrm{O}\left({ }^{1} \mathrm{D}\right)+2 \mathrm{H}$ channel, while the broad underlying signal extending to $E_{\mathrm{KE}} \sim 16000 \mathrm{~cm}^{-1}$ is attributed to the $\mathrm{O}\left({ }^{3} \mathrm{P}\right)+2 \mathrm{H}$ products.

Given the above analysis, the product TKER distribution in Fig. 1D can be divided into three components: $\mathrm{O}\left({ }^{1} \mathrm{D}\right)+2 \mathrm{H}, \mathrm{O}\left({ }^{3} \mathrm{P}\right)+2 \mathrm{H}$ and $\mathrm{OH}+\mathrm{H}$. The first two components are broad features, while the third comprises sharp structures attributable to ro-vibrational levels of the $\mathrm{OH}(\mathrm{A})$ and $\mathrm{OH}(\mathrm{X})$ products. From Fig. 1D, the $\mathrm{O}\left({ }^{1} \mathrm{D}\right)+2 \mathrm{H}$ channel obviously has the highest intensity in the kinetic energy less than 600 $\mathrm{cm}^{-1}$, yet it has never been reported previously in $\mathrm{H}_{2} \mathrm{O}$ photodissociation. The $\mathrm{O}\left({ }^{3} \mathrm{P}\right)+2 \mathrm{H}$ channel clearly makes the major contribution in the higher kinetic energy region. This indicates that the TBD is likely the dominant process following VUV photoexcitation of $\mathrm{H}_{2} \mathrm{O}$ at $107.4 \mathrm{~nm}$. 
Branching ratios for the $\mathrm{O}\left({ }^{1} \mathrm{D}\right)+2 \mathrm{H}, \mathrm{O}\left({ }^{3} \mathrm{P}\right)+2 \mathrm{H}$ and $\mathrm{OH}+\mathrm{H}$ fragmentation channels have been estimated by simulating the TKER distribution (Fig. 1D) using the three components shown in Fig. 2 . Integrating the areas under the respective distributions returns relative $\mathrm{H}$ atom yields for the three channels. Recognizing that two $\mathrm{H}$ atoms are formed in each TBD process, the relative $\mathrm{H}$ atom yields are used to determine the branching ratio, e.g. $67 \%$ at $107.4 \mathrm{~nm}$ for the TBD channels (Table 1).

Photodissociation of $\mathrm{H}_{2} \mathrm{O}$ has also been investigated at eight more VUV wavelengths between $92 \mathrm{~nm}$ and $109 \mathrm{~nm}$, and a similar data analysis procedure is applied at these photolysis wavelengths (see Fig. S3 in the SM). The branching ratios determined for the binary and TBD channels at each wavelength are listed in Table 1. At $109.0 \mathrm{~nm}$, only one TBD channel $\left(\mathrm{O}\left({ }^{3} \mathrm{P}\right)+2 \mathrm{H}\right)$ exists because the $\mathrm{O}\left({ }^{1} \mathrm{D}\right)+2 \mathrm{H}$ channel is energetically not accessible. The results mean that oxygen atoms $\left({ }^{1} \mathrm{D}\right.$ and $\left.{ }^{3} \mathrm{P}\right)$, not $\mathrm{OH}$ radicals, are the major oxygen-containing products from $\mathrm{H}_{2} \mathrm{O}$ photolysis at $\lambda<107.4 \mathrm{~nm}$, in striking contrast to the dominant binary photofragmentation (i.e. $\mathrm{H}+\mathrm{OH}$ ) behaviour displayed by $\mathrm{H}_{2} \mathrm{O}$ photochemistry at longer VUV wavelengths ${ }^{15}$.

The dissociation dynamics of the two TBD channels are also quite interesting. Since the two $\mathrm{H}$ atoms in the water molecule are equivalent, if they dissociate simultaneously it should yield a narrow $\mathrm{H}$ atom kinetic energy distribution, peaking at an $E_{\mathrm{EK}}$ value close to half of the available energy (see Fig. $\mathrm{S} 5$ and S6). However, the observed distributions are much broader than the narrow distributions for a simultaneous concerted process, implying that both TBD processes are due to mostly a sequential dissociation mechanism. Possible dissociation routes for the two channels are illustrated in Fig. 3 (and more details in Fig. S7).

The conclusion that the TBD is the dominant decay process following excitation of $\mathrm{H}_{2} \mathrm{O}$ at these VUV wavelengths could have profound implications for our understanding of the source of oxygen production. For quantitative assessment, we have calculated the fragment-dependent photodissociation rate of $\mathrm{H}_{2} \mathrm{O}$ by using: $J_{\mathrm{H} 2 \mathrm{O}}=\mathbb{} \otimes \Phi_{\lambda} \Gamma \sigma_{\lambda} \mathrm{d} \lambda$, where $\Phi_{\lambda}$ is the solar photon flux, $\Gamma$ is the fragment quantum yield, and $\sigma_{\lambda}$ is the photodissociation cross section[31]. Fig. 4 collects together the wavelength dependences of the solar photon flux in the early period[32], the total photoabsorption cross sections of the parent $\mathrm{H}_{2} \mathrm{O}$ molecule in the VUV region (90-200 nm)[33] and the production yields of $O$ atoms at studied photolysis wavelengths. Convoluting the solar photon flux, the photoabsorption cross sections, and the production yields implies that $\sim 21 \%$ of the photoexcitation events of $\mathrm{H}_{2} \mathrm{O}$ will result in $\mathrm{O}$ atoms. Considering the water abundance in widely interstellar circumstances, like in interstellar clouds ${ }^{2,3}$ and in the comets 67P ${ }^{13}$,[34], oxygen production from water photolysis should be an important process. The following recombination of oxygen atoms will produce molecular oxygen.

In addition, it is well known that water photolysis has nothing to do with oxygen production in the Earth's atmosphere under equilibrium conditions due to VUV photon screening by the thick atmosphere ${ }^{10,35}$. However, in the earliest period of Earth, i.e., the period approaching to clement conditions on the earliest Earth followed by the current Earth-Moon system formed, the surface of Earth remained quite hot (>1000 
K)[35], all of the water on the Earth was vaporized to the atmosphere and part of water clouds (emitted from volcanos or delivered by carbonaceous chondrite meteorites ${ }^{6}$ ) populated at the top of the atmosphere could absorb the VUV photons and dissociate. Given $\left[\mathrm{H}_{2} \mathrm{O}\right]$ is 10 times abundant than $\left[\mathrm{CO}_{2}\right]$ in the atmosphere during this early, chaotic period of Earth ${ }^{6}$ (See Fig. S4 in the SM), the 0-production rate from $\mathrm{H}_{2} \mathrm{O}$ VUV photochemistry could be 3 times larger than that of $\mathrm{CO}_{2}$ in the same VUV wavelength region, via TBD processes: $N_{\mathrm{H} 2 \mathrm{O}}(\mathrm{O}) / N_{\mathrm{CO} 2}(\mathrm{O})=\left(J_{\mathrm{H} 2 \mathrm{O}}(\mathrm{O}) \times\left[\mathrm{H}_{2} \mathrm{O}\right]\right) /\left(J_{\mathrm{CO} 2}(\mathrm{O}) \times\left[\mathrm{CO}_{2}\right]\right)=\sim 3$, where $J_{\mathrm{H} 2 \mathrm{O}}(\mathrm{O})=$ $\sim 5.2 \times 10^{-5} \mathrm{~s}^{-1}$ (Fig. 4), $\mathrm{J}_{\mathrm{CO} 2}(\mathrm{O})=\sim 1.8 \times 10^{-4} \mathrm{~s}^{-1}$ (Fig. S8), $\left[\mathrm{H}_{2} \mathrm{O}\right]$ and $\left[\mathrm{CO}_{2}\right]$ are the densities of $\mathrm{H}_{2} \mathrm{O}$ and $\mathrm{CO}_{2}$, respectively. Since the molecular oxygen generation process should be the same in the three-body recombination process (Eq. 2), this analysis implies that $\mathrm{H}_{2} \mathrm{O}$ photochemistry might be an important prebiotic source of $\mathrm{O}_{2}$ in Earth's early atmosphere.

From the experimental results, it seems that more than one third of $\mathrm{O}$ atoms produced from $\mathrm{H}_{2} \mathrm{O}$ TBD process populate in the metastable ${ }^{1} \mathrm{D}$ state. The generation of $\mathrm{O}\left({ }^{1} \mathrm{D}\right)$ atoms from photodissociation of $\mathrm{H}_{2} \mathrm{O}$ in a significant amount is also very interesting because the metastable $\mathrm{O}\left({ }^{1} \mathrm{D}\right)$ atom is highly reactive[36]. It can react with almost all the gases emitted into the atmosphere. For instance, the reaction of $O\left({ }^{1} D\right)$ with methane could be a significant source of formaldehyde in the earth's primitive atmosphere[37] ${ }^{[38]}$. Thus, the production of $\mathrm{O}\left({ }^{1} \mathrm{D}\right)$ atoms from the exposure of water to VUV radiation, and the subsequent reactions of these atoms, could have been important drivers in the evolution of the earliest atmosphere.

\section{Conclusions}

In the existing interstellar photochemical model, reactions (1) and (2) are the major pathways to produce prebiotic $\mathrm{O}_{2}$. In this work, we propose an alternative prebiotic $\mathrm{O}_{2}$ pathway: atomic oxygen production from the TBD of water, followed by oxygen recombination reactions. Recent International Ultraviolet Explorer (IUE) satellite observation of pre-main-sequence stars suggested that the nascent sun has emitted more than 10 times VUV radiation than it does today[39]. This implies that oxygen formation by VUV photoinduced TBD of $\mathrm{H}_{2} \mathrm{O}$ is likely an important process in the coma of comets, in the interstellar clouds and even in Earth's primitive atmosphere, and thus needs to be incorporated into interstellar photochemical model. Furthermore, the TBD of $\mathrm{H}_{2} \mathrm{O}$ may well be important for oxygen evolution in the atmospheres of all water-rich terrestrial planets[40].

\section{Methods}

The experiments employ a newly constructed apparatus for molecular photochemistry, which is centered on the vacuum ultraviolet free electron laser (VUV-FEL) beam line at the Dalian Coherent Light Source (DCLS) ${ }^{27}$. Briefly, the VUV-FEL facility runs in the high gain harmonic generation (HGHG) mode, in which the seed laser is injected to interact with the electron beam in the modulator (Fig. S1). The seeding pulse, in the wavelength range $\left(\lambda_{\text {seed }}\right) 240-360 \mathrm{~nm}$, can be generated from a picosecond Ti:sapphire laser pulse. 
The electron beam is generated from a photocathode RF gun, and accelerated to the beam energy of $\sim 300 \mathrm{MeV}$ by $7 \mathrm{~S}$-band accelerator structures, with a bunch charge of $500 \mathrm{pC}$. The micro-bunched beam is then sent through the radiator, which is tuned to the $2 \mathrm{nd} / 3 \mathrm{rd} / 4$ th harmonic of the seed wavelength, and coherent FEL radiation with wavelength $\lambda_{\text {seed }} / 2, \lambda_{\text {seed }} / 3$ or $\lambda_{\text {seed }} / 4$ is emitted. Optimization of the linear accelerator yields a high quality electron beam with emittance of $\sim 1.5 \mathrm{~mm} \cdot \mathrm{mrad}$, energy spread of $\sim 1 \%$, and pulse duration of $\sim 1.5 \mathrm{ps}$. In this work, the VUV-FEL operates at $10 \mathrm{~Hz}$, and the maximum pulse energy is $>100 \mu \mathrm{J} /$ pulse. The output wavelength is continuously tunable in the range $50-150 \mathrm{~nm}$ and the typical spectral bandwidth of the VUV-FEL output is $30 \sim 50 \mathrm{~cm}^{-1}$.

The high-n $\mathrm{H}$ atom Rydberg tagging time-of-flight (HRTOF) technique used in this work was pioneered by Welge and coworkers[41]. The key point of this technique is the 1+1' (VUV+UV) excitation of the $\mathrm{H}$ atom. The first step involves VUV laser excitation of the $\mathrm{H}$ atom from its $\mathrm{n}=1$ ground state to the $\mathrm{n}=2$ state by absorbing one $\mathrm{I}=121.57 \mathrm{~nm}$ photon. In the second step, the $\mathrm{H}(\mathrm{n}=2)$ atom is excited with a UV $(\mathrm{I} \sim 365$ $\mathrm{nm}$ ) photon to a high-n ( $\mathrm{n}=30-80)$ Rydberg state. Charged species formed in the interaction region are extracted from the TOF axis by a small electric field $(\sim 20 \mathrm{~V} / \mathrm{cm})$ placed across this region. Rydberg tagged neutral $\mathrm{H}$ atoms fly a known distance $(d » 280 \mathrm{~mm})$ from the interaction region to a rotatable microchannel plate (MCP) Z-stack detector located close behind a grounded fine metal grid. After passing through the grid, the Rydberg atoms are immediately field-ionized by the electric field $(\sim 2000 \mathrm{~V} / \mathrm{cm})$ applied between the grid and the front plate of the Z-stack MCP detector. The signal detected by the MCP is amplified by a fast pre-amplifier and counted by a multichannel scaler.

\section{Declarations}

\section{Acknowledgments}

The experimental work was supported by the National Natural Science Foundation of China (NSFC Center for Chemical Dynamics (Grant No. 21688102)), the National Natural Science Foundation of China (Grant Nos. 21873099, 21922306), the Strategic Priority Research Program of the Chinese Academy of Sciences (Grant No. XDB17000000), the Key Technology Team of the Chinese Academy of Sciences (Grant No. GJJSTD20190002), and the international partnership program of Chinese Academy of Sciences (No. 121421KYSB20170012). The theoretical work was supported by the National Natural Science Foundation of China (Grant Nos. 21590802, 21733006, and 91641104). MNRA is grateful for funding from the Engineering and Physical Sciences Research Council (EPSRC, EP/L005913) and to the NFSC Center for Chemical Dynamics for the award of a Visiting Fellowship.

\section{Supplementary materials}

Absorption spectrum of $\mathrm{H}_{2} \mathrm{O}$, experimental results at eight more VUV wavelengths, the relative abundances of gases in the early atmosphere of the Earth, the illustration of TBD pathways, electronic structure considerations, oxygen production rate for $\mathrm{CO}_{2}$, supplementary figures and references. 


\section{Author Contributions}

K.J.Y. and X.M.Y. designed the experiments. Y.C., Y.Y., Z.J.L., Q.M.L., J.Y.Y., and Z.C.C. performed the experiments. X.Z., D.H.Q., K.J.Y., M.N.R.A., L.C., W.Q.Z., G.R.W., and X.M.Y. discussed the experimental results. F.A., X.X.H., and D.Q.X. performed the theoretical calculations. K.J.Y., M.N.R.A., and X.M.Y. prepared the manuscript.

\section{Competing interests}

The authors declare no competing interests.

\section{Table}

Table 1 The branching ratios for the binary and TBD channels following $\mathrm{H}_{2} \mathrm{O}$ photodissociation at different VUV wavelengths $(\mathrm{nm})$. The maximum uncertainty on the branching ratios is $\pm 10 \%$.

\begin{tabular}{|c|c|c|c|c|c|c|c|c|c|}
\hline \multirow{2}{*}{$\begin{array}{l}\text { Dissociation } \\
\text { Channel }\end{array}$} & \multicolumn{9}{|c|}{ Photolysis Wavelength (nm) } \\
\hline & 109.0 & 107.4 & 106.7 & 105.7 & 101.3 & 98.1 & 96.2 & 94.5 & 92.0 \\
\hline $\begin{array}{l}\text { TBD } \\
\left(O\left({ }^{1} D /{ }^{3} P\right)+2 H\right)\end{array}$ & 0.35 & 0.67 & 0.76 & 0.62 & 0.77 & 0.72 & 0.79 & 0.86 & 0.86 \\
\hline $\begin{array}{l}\text { Binary Dissociation: } \\
(\mathrm{H}+\mathrm{OH})\end{array}$ & 0.65 & 0.33 & 0.24 & 0.38 & 0.23 & 0.28 & 0.21 & 0.14 & 0.14 \\
\hline
\end{tabular}

\section{References}

[1]. Goldsmith, P. F. et al. Herschel Measurements of molecular oxygen in Orion. Astrophys. J. 737, 96 (2011).

[2]. Liseau, R. et al. Multi-line detection of $\mathrm{O}_{2}$ toward $\rho$ Ophiuchi A. Astron. Astrophys. 541, A73 (2012).

[3]. Hall, D. T. et al. Detection of an oxygen atmosphere on Jupiter's moon Europa. Nature 373, 677-679 (1995).

[4]. Johnson, R. E. et al. Production, ionization and redistribution of $\mathrm{O}_{2}$ in Saturn's ring atmosphere. Icarus 180, 393-402 (2006).

[5]. Barker, E. S. Detection of molecular oxygen in the martian atmosphere. Nature 238, 447-448 (1972). 
[6]. Zahnle, K., Schaefer, L. \& Fegley, B. Earth's earliest atmospheres. Cold Spring Harb. Perspect. Biol. 2, a004895 (2010).

[7]. Luo, G. M. et al. Rapid oxygenation of Earth's atmosphere 2.33 billion years ago. Sci. Adv. 2, e1600134 (2016).

[8]. Holland, H. D. The oxygenation of the atmosphere and oceans. Philos. T. R. Soc. B 361, 903-915 (2006).

[9]. Kasting, J. F., Liu, S. C. \& Donahue, T. M. Oxygen Levels In the Prebiological Atmosphere. J. Geophys. Res-Oc. Atm. 84, 3097-3107 (1979).

[10]. Lu, Z., Chang, Y. C., Yin, Q. Z., Ng, C. Y. \& Jackson, W. M. Evidence for direct molecular oxygen production in $\mathrm{CO}_{2}$ photodissociation. Science $346,61-64$ (2014).

[11]. Wang, X. D., Gao, X. F., Xuan, C. J. \& Tian, S. X. Dissociative electron attachment to $\mathrm{CO}_{2}$ produces molecular oxygen. Nat. Chem. 8, 258-263 (2016).

[12]. Young, E.D. Strange water in the solar system. Science, 317, 211-212 (2007).

[13]. Bieler, A. et al. Abundant molecular oxygen in the coma of comet 67P/Churyumov -Gerasimenko. Nature 526, 678-681 (2015).

[14]. Yao, Y. X. \& Giapis, K. P. Dynamic molecular oxygen production in cometary comae. Nat. Commun. 8, 15298 (2017).

[15]. Yuan, K. J., Dixon, R. N. \& Yang, X. M. Photochemistry of the water molecule: adiabatic versus nonadiabatic dynamics. Acc. Chem. Res. 44, 369-378 (2011).

[16]. Yuan, K. J. et al. Nonadiabatic dissociation dynamics in $\mathrm{H}_{2} \mathrm{O}$ : competition between rotationally and nonrotationally mediated pathways. Proc. Natl. Acad. Sci. U.S.A. 105, 19148-19153 (2008).

[17]. Engel, V., Schinke, R. \& Staemmler, V. Photodissociation dynamics of $\mathrm{H}_{2} \mathrm{O}$ and $\mathrm{D}_{2} \mathrm{O}$ in the 1 st absorption-band - a complete ab initio treatment. J. Chem. Phys. 88, 129-148 (1988).

[18]. Brouard, M., Langford, S. R. \& Manolopoulos, D. E. New trends in the state-to-state photodissociation dynamics of $\mathrm{H}_{2} \mathrm{O}(\mathrm{A})$. J. Chem. Phys. 101, 7458-7467 (1994).

[19]. Yang, X. F., Hwang, D. W., Lin, J. J. \& Yang, X. Dissociation dynamics of the water molecule on the $A^{1} B_{1}$ electronic surface. J. Chem. Phys. 113, 10597-10604 (2000).

[20]. van Harrevelt, R. \& van Hemert, M. C. Photodissociation of water. I. electronic structure calculations for the excited states. J. Chem. Phys. 112, 5777-5786 (2000). 
[21]. Dixon, R. N. et al. Chemical "double slits": dynamical interference of photodissociation pathways in water. Science 285, 1249-1253 (1999).

[22]. Fillion, J. H. et al. Photodissociation of $\mathrm{H}_{2} \mathrm{O}$ and $\mathrm{D}_{2} \mathrm{O}$ in $\mathrm{B}, \mathrm{C}$, and $\mathrm{D}$ states (134-119 nm). Comparison between experiment and ab initio calculations. J. Phys. Chem. A 105, 11414-11424 (2001).

[23]. Mordaunt, D. H., Ashfold, M. N. R. \& Dixon, R. N. Dissociation dynamics of $\mathrm{H}_{2} \mathrm{O}\left(\mathrm{D}_{2} \mathrm{O}\right)$ following photoexcitation at the lyman-alpha wavelength (121.6 nm). J. Chem. Phys. 100, 7360-7375 (1994).

[24]. On the basis of thermodynamic calculations with the data available from the thermochemical network (https://atct.anl.gov) and references therein.

[25]. Harich, S. A. et al. Photodissociation of $\mathrm{H}_{2} \mathrm{O}$ at $121.6 \mathrm{~nm}$ : a state-to-state dynamical picture. J. Chem. Phys. 113, 10073-10090 (2000).

[26]. Slanger, T. G. \& Black, G. Photodissociative channels at $1216 \AA$ for $\mathrm{H}_{2} \mathrm{O}, \mathrm{NH}_{3}$, and $\mathrm{CH}_{4}$. J. Chem. Phys. 77, 2432-2437 (1982).

[27]. H. L. Wang, et al., Photodissociation dynamics of $\mathrm{H}_{2} \mathrm{O}$ at $111.5 \mathrm{~nm}$ by a vacuum ultraviolet free electron laser. J. Chem. Phys. 148,124301 (2018).

[28]. Fillion, J. H. et al. High resolution photoabsorption and photofragment fluorescence spectroscopy of water between 10.9 and $12 \mathrm{eV}$. J. Chem. Phys. 120, 6531-6541 (2004).

[29]. The total kinetic energy can be derived using the following equation, $E_{\mathrm{KE}}=$, where $d$ is the flying path length of $\mathrm{H}$ atom $(d \approx 28 \mathrm{~cm})$ from the photodissociation region to the detector, $t$ is the measured time of flight.

[30]. Boyarkin, O. V. et al. Accurate bond dissociation energy of water determined by triple-resonance vibrational spectroscopy and ab initio calculations. Chem. Phys. Lett. 568, 14-20 (2013).

[31]. Heays, A. N., Bosman, A. D. \& van Dishoeck, E. F. Photodissociation and photoionization of atoms and molecules of astrophysical interest. Astron. Astrophys. 602, A105 (2017).

[32]. Zahnle, K. J. \& Walker, J. C. G. The evolution of solar ultraviolet luminosity. Rev. Geophys. Space Phys. 20, 280-292 (1982).

[33]. Lee, L. C. \& Suto, M. Quantitative photoabsorption and fluorescence study of $\mathrm{H}_{2} \mathrm{O}$ and $\mathrm{D}_{2} \mathrm{O}$ at 50-190 nm. Chem. Phys. 110, 161-169 (1986).

[34]. Hassig, M. et al. Time variability and heterogeneity in the coma of 67P/Churyumov-Gerasimenko. Science 347, aaa0276 (2015).

[35]. Sleep, N. H. The Hadean-Archaean environment. Cold Spring Harb. Perspec. Biol. 2, a002527 (2010). 
[36]. Tachiev, G. I. \& Fischer, C. F. Breit-Pauli energy levels and transition rates for nitrogen-like and oxygenlike sequences. Astron. Astrophys. 385, 716-723 (2002).

[37]. Lin, J. J., Shu, J., Lee, Y. T. \& Yang, X. Multiple dynamical pathways in the $\mathrm{O}\left({ }^{1} \mathrm{D}\right)+\mathrm{CH}_{4}$ reaction: A comprehensive crossed beam study. J. Chem. Phys. 113, 5287-5301 (2000).

[38]. Yung, Y. L. \& Demore, W. B. Photochemistry of Planetary Atmosphere (Oxford Univ. Press, New York, 1999).

[39]. Zahnle, K. J., Gacesa, M. \& Catling, D. C. Strange messenger: A new history of hydrogen on Earth, as told by Xenon. Geochim. Cosmochim. Ac. 244, 56-85 (2019).

[40]. Zeng, L. \& Sasselov, D. The effect of temperature evolution on the interior structure of $\mathrm{H}_{2} \mathrm{O}$-rich planets. Astrophys. J. 784, 96 (2014) and references therein.

[41]. Schnieder, L. et al. Photodissociation dynamics of $\mathrm{H}_{2} \mathrm{~S}$ at $121.6 \mathrm{~nm}$ and a determination of the potential energy function of $\mathrm{SH}\left(\mathrm{A}^{2} \Sigma^{+}\right)$. J. Chem. Phys. 92, 7027-7037 (1990).

[42]. van Dishoeck, E. F., Herbst, E. \& Neufeld, D. A. Interstellar water chemistry: From laboratory to observations. Chem. Rev. 113, 9043-9085 (2013).

[43]. Fillion, J. H. et al. Ionization yield and absorption spectra reveal superexcited Rydberg state relaxation processes in $\mathrm{H}_{2} \mathrm{O}$ and $\mathrm{D}_{2}$ O. J. Phys. B: At. Mol. Opt. Phys. 36, 2767-2776 (2003).

\section{Figures}




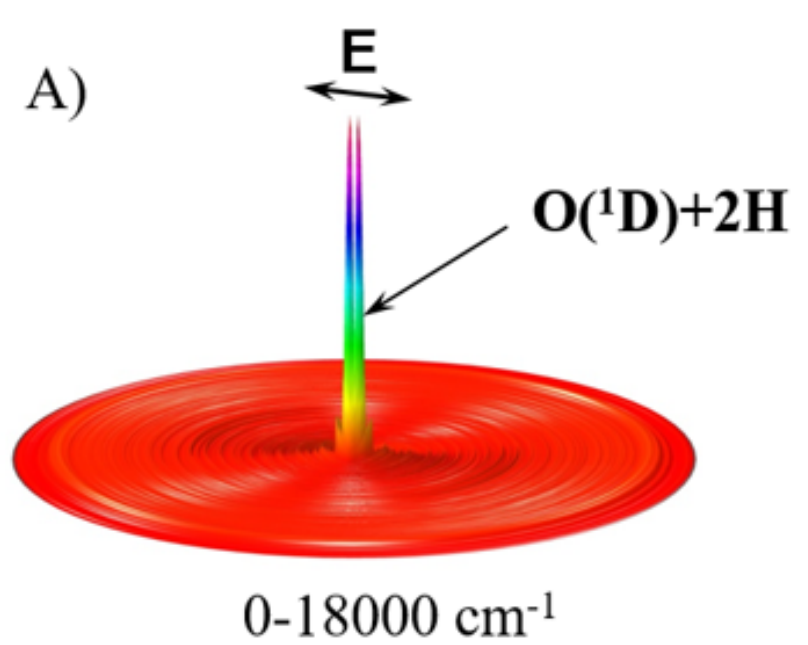

B)

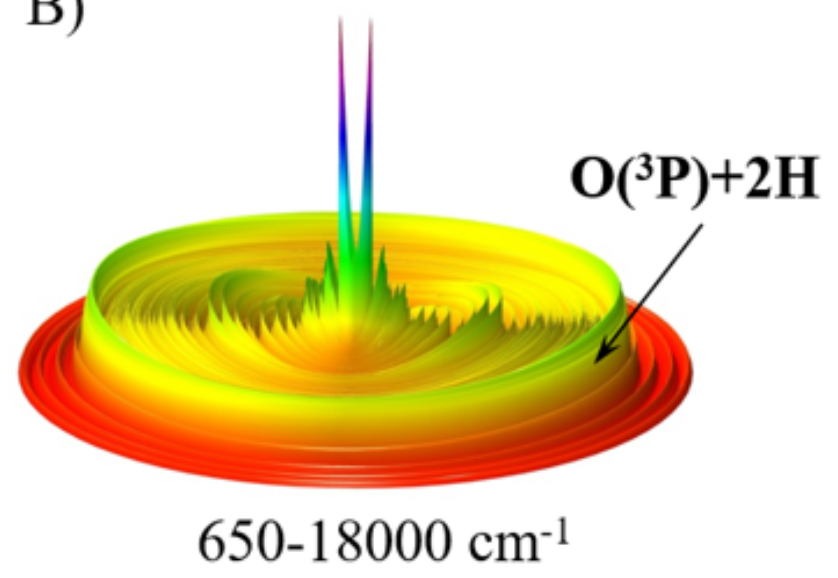

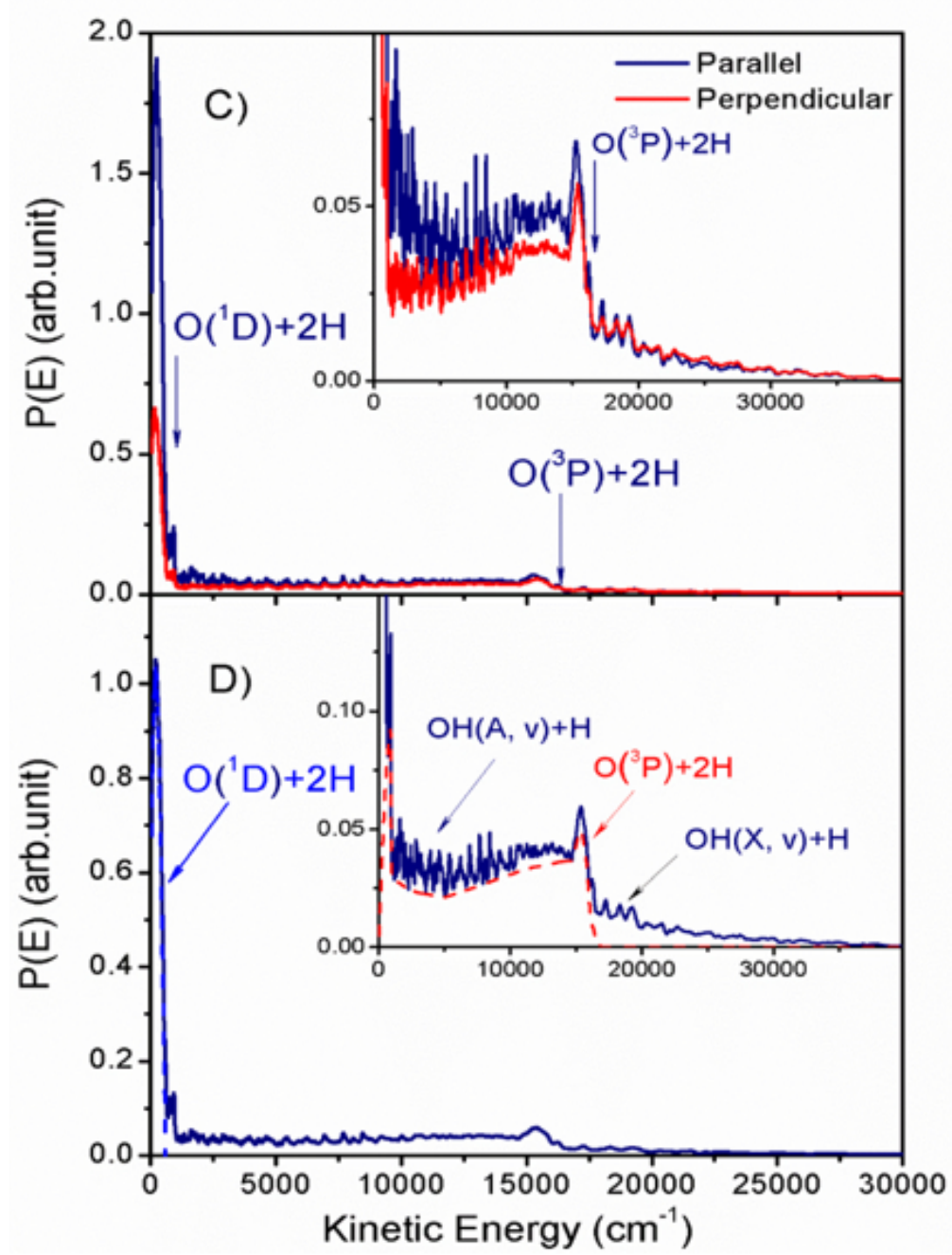

Figure 1

A) The 3D product contour diagram from the photodissociation of $\mathrm{H} 2 \mathrm{O}$ at $107.4 \mathrm{~nm}$ for the total kinetic energy release (TKER) between 0 to $18,000 \mathrm{~cm}-1$; B) The 3D product contour diagram for the TKER between 650 to $18,000 \mathrm{~cm}-1$. C) The product TKER distributions at I $=107.4 \mathrm{~nm}$ with the detection axis parallel and perpendicular to the polarization vector of the VUV-FEL radiation. The energetic limits of the two TBD channels (EKEmax $\sim 580 \mathrm{~cm}-1$ and $~ 16448 \mathrm{~cm}-1$ ) are marked, and the inset displays the same spectra on an expanded vertical scale. D) The product TKER distribution at I $=107.4 \mathrm{~nm}$ with the detection axis at 54.7o (magic angle) to the polarization direction, along with the simulated TKER distributions for the $\mathrm{O}(1 \mathrm{D})+2 \mathrm{H}$ and $\mathrm{O}(3 \mathrm{P})+2 \mathrm{H}$ TBD channels. 


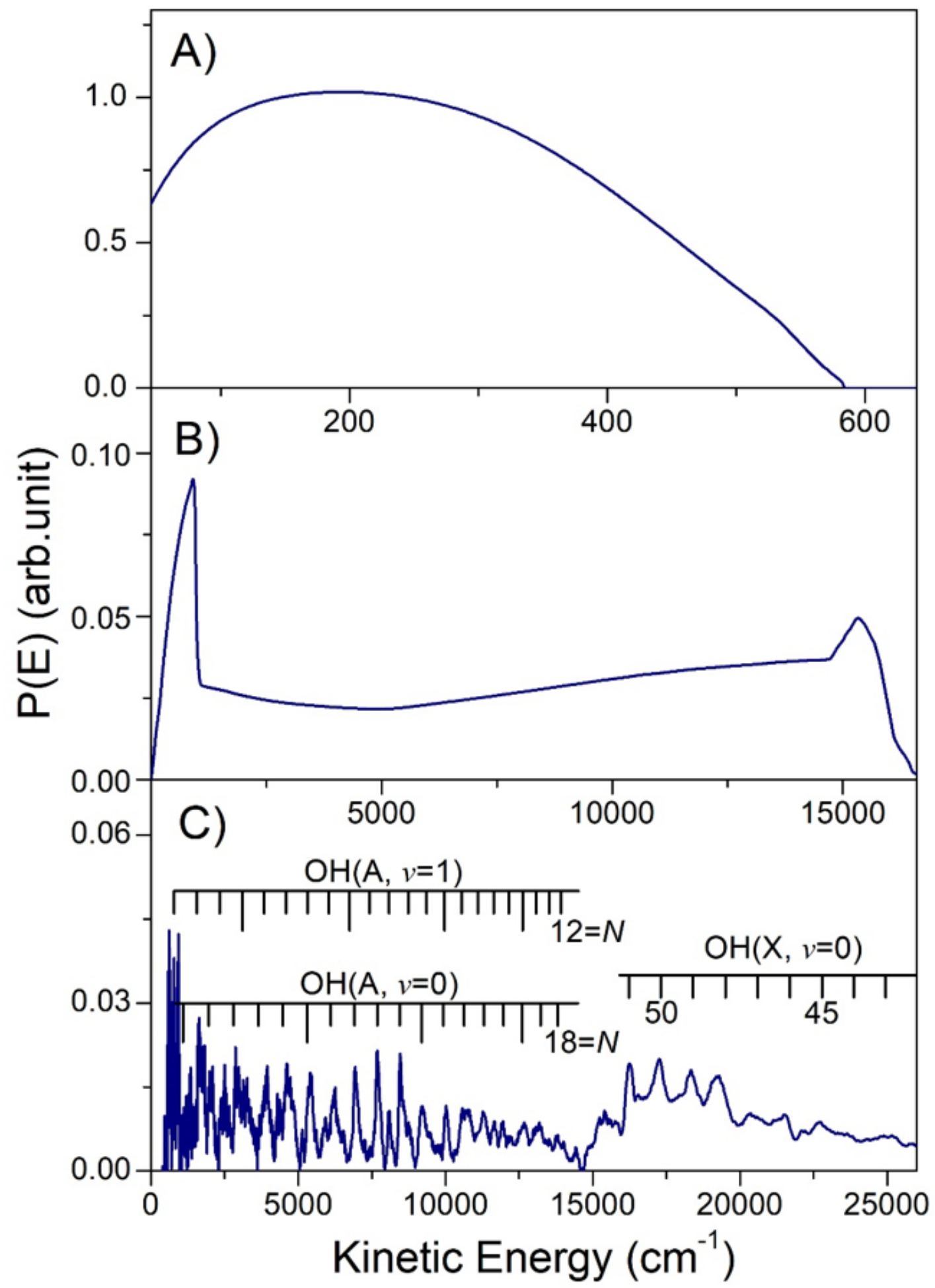

Figure 2

TKER distributions determined from simulating the (A) $\mathrm{O}(1 \mathrm{D})+2 \mathrm{H}$, (B) $\mathrm{O}(3 \mathrm{P})+2 \mathrm{H}$ and (C) $\mathrm{OH}+\mathrm{H}$ product yields from photodissociation of $\mathrm{H} 2 \mathrm{O}$ at $\mathrm{I}=107.4 \mathrm{~nm}$. The sharp features in the $\mathrm{H}+\mathrm{OH}$ product yield have been assigned to population of rovibrational levels of the $\mathrm{X}$ and $\mathrm{A}$ states of the $\mathrm{OH}$ radical. 


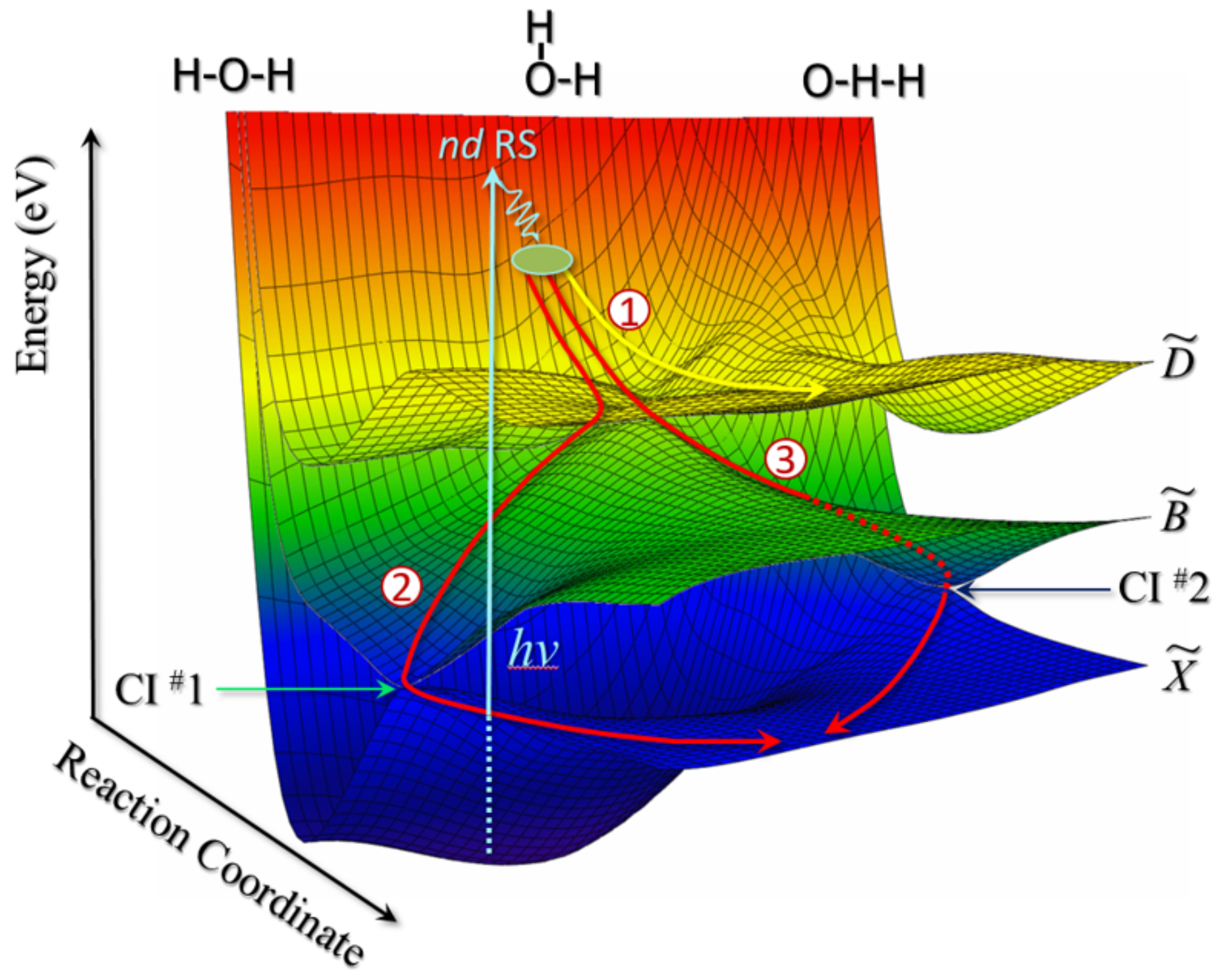

Figure 3

Illustration of the TBD mechanisms of $\mathrm{H} 2 \mathrm{O}$ upon VUV excitation. Photoexcitation populates the nd Rydberg states (nd RS) which undergo efficient non-adiabatic coupling to the $D^{\sim}$ state. Path 1 illustrates the possible direct dissociation route from the $\mathrm{D}^{\sim}$ state to form $\mathrm{O}(1 \mathrm{D})+2 \mathrm{H}$ products. Paths 2 and 3 illustrate plausible routes for the more complicated $\mathrm{O}(3 \mathrm{P})+2 \mathrm{H}$ dissociation paths: from the $\mathrm{D}^{\sim}$ state to the $\mathrm{B}^{\sim}$ state and then to the ground state via the two conical intersections $(\mathrm{Cl} \# 1$ or $\mathrm{Cl} \# 2)$, following the initial internal conversion from the excited nd RS to the $D^{\sim}$ state. This picture is consistent with the observed angular anisotropy for the two channels: the $\mathrm{O}(1 \mathrm{D})+2 \mathrm{H}$ channel is a more direct dissociation process with larger angular anisotropy, while the $\mathrm{O}(3 \mathrm{P})+2 \mathrm{H}$ channel is a more complicated dissociation process with smaller angular anisotropy. 

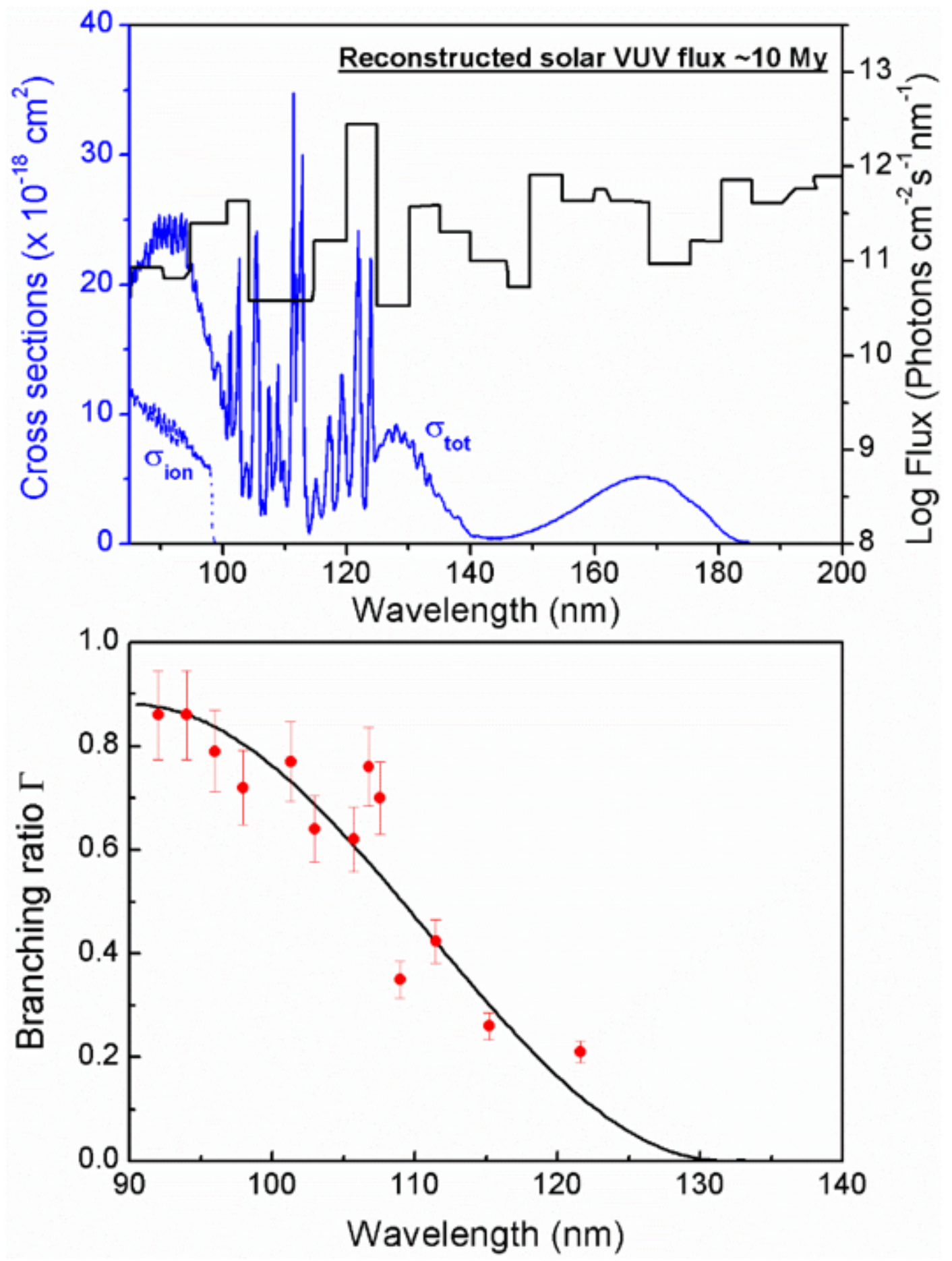

Figure 4

Plot showing the wavelength dependences of the reconstructed VUV solar flux (90-200 nm) at $10 \mathrm{My}$ $(10 \mathrm{My}=1 \times 107$ years, reconstructed from Ref. 32 . The VUV solar flux at modern period or the interstellar radiation field (ISRF) also can be used, which may modify the yield of O-production a little, but the final

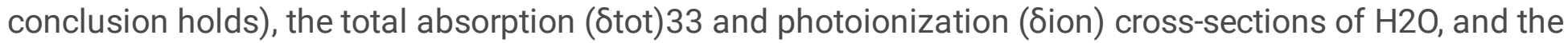
quantum yield for forming 0 -atom photoproducts $(\mathrm{O}(3 \mathrm{P} / 1 \mathrm{D})+2 \mathrm{H}), \Gamma$, determined in the present work. It is noted that the predissociation rate of $\mathrm{H} 2 \mathrm{O}$ is sufficiently fast that the fluorescence quantum yield must be 
negligible, so the total photodissociation cross-section will be almost the same as the photoabsorption cross-section. The sigmoidal function through the latter data is used to derive the reported overall 0 product quantum yield. The quantum yields at I $=111.5 \mathrm{~nm}, 115.2 \mathrm{~nm}, 121.57 \mathrm{~nm}$ are obtained from Refs. 15, 25 and 27.

\section{Supplementary Files}

This is a list of supplementary files associated with this preprint. Click to download.

- ThreeBodyDissociationofWaterSM.docx 